\title{
EFISIENSI EKONOMI DAN SKALA USAHA TEKNOLOGI BUDIDAYA UDANG WINDU (Penaeus monodon) DI JAWA TIMUR
}

\author{
Ali Musa Pasaribu*)
}

\begin{abstract}
ABSTRAK
Budidaya udang windu di tambak membutuhkan alokasi masukan produksi secara efisien, untuk meningkatkan produktivitas dan keuntungan maksimum. Tingginya biaya pengelolaan pakan dan air serta investasi pada teknologi budidaya intensif telah mengakibatkan alokasi masukan produksi menjadi tidak efisien, menyebabkan biaya produksi udang akan lebih tinggi jika dibandingkan dengan teknologi semiintensif dan ekstensif.

Penelitian ini bertujuan untuk mengetahui efisiensi ekonomi teknologi budidaya udang dan kondisi skala usaha teknologi budidaya udang secara agregat yang diterapkan oleh petani atau pengusaha (intensif, semiintensif, dan ekstensif) di Jawa Timur.

Penelitian menggunakan metode survai dan data yang diperoleh dianalisis dengan fungsi keuntungan translog dengan memasukkan delapan variabel masukan berubah, lima variabel masukan tetap dan ditambah dengan teknologi sebagai variabel boneka.

Di dalam pelaksanaan penelitian ini diperoleh kesimpulan bahwa pada musim tanam ke satu (penghujan), teknologi semiintensif lebih efisien dalam mengalokasikan masukan produksi dibandingkan dengan teknologi intensif dan ekstensif. Selanjutnya pada musim tanam ke dua (kemarau), ketiga teknologi tersebut tidak menunjukkan efisiensi yang berbeda. Pada musim tanam ke satu kondisi skala usaha budidaya udang berada pada increasing return to scale (IRTS), sedangkan pada musim tanam ke dua skala usaha berada pada kondisi constant return to scale (CRTS).
\end{abstract}

\section{ABSTRACT: Efficiency and Economic Scale of Shrimp (Penaeus monodon) Culture Technology in East Java. By. Ali Musa Pasaribu.}

Shrimp culture in brackishwater pond required efficient production input allocation to maximize productivity and profit. The high cost of feed, water management and investment of intensive culture technology farming have made inefficient production input allocation. Consequently it causes higher production cost compared to that of semiintensive and extensive technology farming.

The purpose of the study is to know the economical efficiency of shrimp culture technology and the condition of shrimp culture technology level (intensive, semiintensive, and extensive) in East Java.

The study used survey method. Data were analyzed by using translog profit functions model with 8 dependend variable inputs, 5 fixed variable inputs and technology as a dummy variable.

The study concluded that the first farming season of the semiintensive technology was more efficient than the intensive and extensive technologies. The second farming season had same efficiency for all technologies. At the first farming season, the shrimp culture farming level condition had an increasing return to scale (IRTS), while at the second farming season, it had a constant return to scale (CRTS).

\section{KEYWORDS: Economic eficiency; economic scale; shrimp culture technology}

\section{PENDAHULUAN}

Budidaya udang windu di tambak memerlukan alokasi sumber daya yang efisien untuk meningkatkan produktivitas dan keuntungan maksimum. Propinsi Jawa Timur merupakan sentra produksi udang windu budidaya di tambak terbesar di Indonesia, jika dibandingkan dengan propinsi lainnya (Anonim., 1993). Teknologi budidaya udang intensif, semiintensif, dan ekstensif

*) Peneliti pada Balai Penelitian Perikanan Pantai 
berbeda dalam mengalokasikan masukan produksi yang bergantung pada padat penebaran benur (Cholik et al., 1989), sehingga makin tinggi kepadatan benur makin besar pula alokasi masukan produksi yang digunakan.

Upaya petani atau pengusaha budidaya tambak udang untuk memperoleh tingkat keuntungan normal pada jangka panjang membutuhkan suatu manajemen produksi yang efisien, terutama dalam menggunakan alokasi pakan dan pengelolaan kualitas air sebagai masukan produksi. Budidaya udang di tambak memerlukan sarana produksi (saprodi) seperti benur, pakan, obat, tenaga kerja, pupuk kimia, kapur pertanian (kaptan), bahan bakar minyak solar dan tenaga listrik.

Peningkatan efisiensi ekonomi produksi sangat penting bagi peningkatan keuntungan dan daya saing. Menurut Simatupang (1988), peningkatan efisiensi ekonomi dapat dilakukan dengan mempergunakan teknologi yang ada dengan baik, mempergunakan masukan yang optimal dan memiliki skala usaha yang optimal.

Penggunaan pakan dan air paling banyak pada teknologi budidaya udang intensif, sedangkan pada teknologi semiintensif penggunaan pakan dan air jauh lebih sedikit dibandingkan intensif. Teknologi ekstensif penggunaan air (pasok dan buang) semata-mata bergantung pada pakan alami yang ditumbuhkan dengan pemupukan. Pada teknologi intensif, pemberian pakan yang berlebihan dan tidak mengacu pada kebutuhan optimal, dapat menimbulkan konversi pakan yang tinggi, sehingga mengakibatkan tingginya biaya produksi (Anonim., 1992; Poernomo, 1988).

Pengkajian alokasi penggunaan masukan produksi usahatani tambak udang di Indramayu, Jawa Barat yang dilakukan oleh Partagunawan (1990), diperoleh hasil bahwa kondisi skala usahatani tambak udang pada teknologi ekstensif dan semiintensif berada pada kondisi skala usaha ke-naikan hasil (increasing return to scale; IRTS). Perlu diteliti lebih lanjut seberapa jauh alokasi penggunaan masukan produksi yang efisien dan pada kondisi skala usaha yang bagaimana budidaya udang dilaksanakan di Jawa Timur.

Berdasarkan hasil penelitian tersebut di atas (Partagunawan, 1990), maka ketiga tingkatan teknologi tersebut (intensif, semiintensif, dan ekstensif) belumlah lengkap informasinya mengenai efisiensi ekonomi dan kondisi skala usaha menurut spesifik lokasi, sehingga perlu dilanjutkan penelitiannya. Penelitian bertujuan untuk: (1) mengetahui efisiensi ekonomi masukan produksi pada berbagai tingkat teknologi yang diterapkan oleh petani atau pengusaha tambak udang di Jawa Timur; (2) mengetahui kondisi skala ekonomi usahatani budidaya udang yang dikelola petani atau pengusaha ditinjau secara agregat pada ketiga teknologi yang digunakan.

Skala usaha budidaya udang intensif pada umumnya lebih besar dibandingkan dengan semiintensif dan ekstensif. Menurut Bilas (1984), semakin besar skala usaha sampai batas tertentu akan diperoleh hasil produksi yang semakin naik (increasing return to scale). tetapi setelah mencapai tingkat usaha tertentu akan diperoleh hasil produksi yang tetap (constant return to scale) dan semakin menurun (decreasing return to scale). Selanjutnya, Yusdja dan Saragih (1983) mengatakan usahatani dengan skala besar tidak akan selalu mendapat keuntungan yang lebih besar disebabkan belum efisiennya biaya masukan produksi, harga produksi yang berfluktuasi, dan tingkat produktivitas yang rendah.

Hipotesis yang diajukan sebagai dasar pertimbangan untuk melaksanakan penelitian adalah: (1) pada musim tanam ke satu (penghujan), efisiensi ekonomi masukan produksi pada teknologi semiintensif lebih efisien dibandingkan dengan teknologi intensif dan ekstensif. Selanjutnya pada musim tanam ke dua (kemarau) teknologi intensif, semiintensif, dan ekstensif memiliki tingkat efisiensi ekonomi yang sama; (2) usaha teknologi budidaya udang intensif, semiintensif, dan ekstensif pada musim tanam ke satu berlangsung pada kondisi skala usaha pada kenaikan hasil yang naik (increasing return to scale), dan pada musim tanam ke dua berlangsung pada kondisi skala usaha kenaikan hasil yang tetap (constant return to scale)

\section{BAHAN DAN METODE}

Penelitian menggunakan metode survai, sehingga sampel yang diambil dapat menggambarkan budidaya udang di Jawa Timur.

Penelitian dilakukan mulai bulan Oktober 1993 sampai dengan Maret 1994 (musim penghujan) disebut musim tanam ke satu, dan 
berlanjut pada musim tanam ke dua, yaitu bulan April sampai dengan Agustus 1994 (musim kemarau). Pengambilan sampel secara purposive rumah tangga petani budidaya udang dilakukan pada 4 daerah tingkat II Kabupaten, yaitu Gresik, Sidoarjo, Situbondo, dan Banyuwangi.

Sebagai unit penelitian yang terpilih diambil rumah tangga petani atau pengusaha sebagai sampel dengan menggunakan rumus Parrel et al. (1973), yaitu:

$$
N=N 1+N 2+N 3
$$

atau

$$
N=\sum_{i=1}^{N} N i
$$

di mana :

$\mathrm{Ni}=$ jumlah rumah tangga petani/pengusaha pada stratum ke $i$

$\mathrm{N}=$ jumlah populasi rumah tangga petani/peng. usaha tambak udang pada sasaran populasi didasarkan pada stratum

Penarikan sampel dilakukan dengain metode acak berlapis (stratified random sampling). Sampel yang diambil dimasukkan ke dalam masing-masing lapisan dengan menggunakan rumus Cochran (1977), yaitu:

$$
n i=\frac{N i}{N} n
$$

di mana:

$$
\mathrm{n}=\text { jumlah sampel keseluruhan }
$$

$\mathrm{N}=$ jumlah populasi rumah tangga petani atau pengusaha tambak udang pada sasaran populasi didasarkan pada stratum

$\mathrm{Ni}=$ jumlah rumah tangga petani atau peng. usaha pada stratum ke

ni $=$ jumlah sampel yang harus diambil dari stratum ke i

Untuk ukuran sampel keseluruhan (n), ditentukan sebesar $10 \%$ guna dapat memperoleh (ni) sebagai ukuran sampel yang akan diambil berdasarkan stratum. Kalau seandainya ukuran populasi $(\mathrm{Ni})$ relatif kecil, maka akan diambil secara sensus.

Sampel yang diambil berdasarkan tingkat teknologi semuanya adalah: (1) tambak udang ekstensif 52 petak; (2) tambak udang semiintensif sebanyak 48 petak; dan (3) tambak udang intensif sebanyak 100 petak, sehingga jumlah percontoh yang diambil 200 petak.
Analisis data untuk pengujian hipotesis dilakukan dengan menggunakan pendekatan fungsi keuntungan translog yang pernah digunakan oleh Sidhu dan Baanante (1981). Ketiga tingkatan teknologi tambak (intensif, semiintensif, dan ekstensif) menggunakan delapan faktor produksi tidak tetap, yaitu benur, pakan, obat, tenaga kerja, pupuk kimia, kaptan, bahan bakar minyak solar, tenaga listrik, dan lima faktor produksi tetap, yaitu luas lahan, konstruksi kolam, bangunan sipil, bangunan irigasi, dan peralatan kincir. Selain itu teknologi digunakan sebagai variabel boneka yang menggambarkan ketiga tingkatan teknologi tersebut.

Fungsi keuntungan translog dapat diformulasikan sebagai berikut:

$$
\begin{aligned}
\ln \pi^{*}= & \alpha_{0}^{*}+\sum_{i=1}^{n} \operatorname{Ln} P^{*}+\sum_{i=1}^{n} \sum_{h=1}^{n} \gamma_{i h} \operatorname{Ln} P_{i}^{\cdot} \operatorname{Ln} P_{h}^{*}+ \\
& \sum_{i=1}^{n} \sum_{h=1}^{m} d_{i k} \operatorname{Ln} P_{i}^{*} \operatorname{Ln} Z_{k}+\sum_{h=1}^{m} \beta_{k} \operatorname{Ln} Z_{k}+ \\
& \sum_{k=1}^{m} \sum_{j=1}^{m} \phi_{k j} \operatorname{Ln} Z_{k} \operatorname{Ln} Z_{j}+\ldots \ldots \ldots \ldots \ldots . . .(3)
\end{aligned}
$$

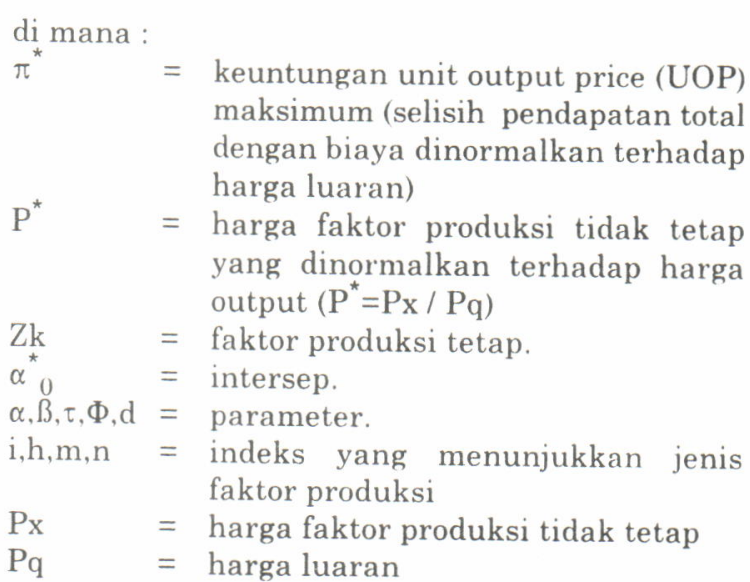

Pengujian hipotesis untuk mengukur efisiensi ekonomi dilakukan dengan membandingkan besarnya koefisien variabel boneka teknologi dengan kaidah keputusan sebagai berikut:

$$
\begin{aligned}
& \text { Jika Ho : } \Phi 1=\Phi 2 \text {, diterima } \\
& \text { H1 : } \Phi 1 \neq \Phi 2 \text {, ditolak } \\
& \text { di mana: } \\
& \Phi=\text { koefisien variabel boneka teknologi } \\
& \Phi 1=\text { semiintensif } \\
& \Phi 2=\text { intensif dan ekstensif }
\end{aligned}
$$


Selanjutnya untuk hipotesis dalam mengukur kondisi skala ekonomi usahatani budidaya udang adalah sebagai berikut:

$\mathrm{Ho}_{\mathrm{o}}=\Sigma \beta \mathrm{k}+\Sigma \Sigma \Phi \mathrm{kj} \leq 1$, diterima

$\mathrm{H} 1=\Sigma \mathrm{Bk}+\Sigma \Sigma \Phi \mathrm{kj}>1$ ditolak

\section{HASIL DAN PEMBAHASAN}

Hasil analisis data menunjukkan bahwa uji efisiensi ekonomi budidaya udang pada musim tanam ke satu dan ke dua di Jawa Timur tahun 1993 dan 1994 disajikan pada Tabel 1.
Selanjutnya hasil analisis data untuk skala usaha budidaya udang pada musim tanam ke satu dan ke dua tahun 1993-1994 dapat dilihat pada Tabel 2 .

Uji skala usaha pada musim tanam ke satu secara agregat telah berlangsung pada kondisi skala usaha pertambahan hasil yang naik atau increasing return to scale (IRTS) dan pada musim tanam ke dua berada pada kondisi skala usaha pertambahan hasil yang tetap atau constant return to scale (CRTS). Pada musim tanam ke satu, teknologi semiintensif lebih efisien di-

Tabel 1. Uji efisiensi ekonomi budidaya udang pada musim tanam ke satu dan ke dua di Jawa Timur tahun 1993 dan 1994

Table 1. Economic efficiency test of shrimp culture at the first planting season and second planting season in East Java, 1993/1994.

\begin{tabular}{|c|c|c|c|c|}
\hline $\begin{array}{c}\text { Musim tanam } \\
\text { Planting season }\end{array}$ & $\begin{array}{c}\text { Hipotesis } \\
\text { Hypothesis }\end{array}$ & Testing & T.cal. & $\begin{array}{c}\text { Keputusan } \\
\text { Decision }\end{array}$ \\
\hline (1) & $\begin{array}{l}\text { Ho : } \Phi_{1}=0 \\
\text { H1 : } \Phi_{1} \neq 0 \\
\text { Ho : } \Phi_{2}=0 \\
\text { H1 : } \Phi_{2} \neq 0\end{array}$ & $\begin{array}{l}\text { intensive vs others } \\
\text { s.intensive vs others }\end{array}$ & $\begin{array}{l}-0.4862 \\
-2.5654 * * *\end{array}$ & $\begin{array}{l}\text { Accept Ho } \\
\text { Reject Ho }\end{array}$ \\
\hline (2) & $\begin{array}{l}\text { Ho : } \Phi_{1}=0 \\
\text { H1 : } \Phi_{1} \neq 0 \\
\text { Ho : } \Phi_{2}=0 \\
\text { H1 : } \Phi_{2} \neq 0\end{array}$ & $\begin{array}{l}\text { intensive vs others } \\
\text { s.intensive vs others }\end{array}$ & $\begin{array}{l}1.5276 \\
0.4995\end{array}$ & $\begin{array}{l}\text { Accept Ho } \\
\text { Accept Ho }\end{array}$ \\
\hline
\end{tabular}

${ }^{* * *}$ ) signifikan pada $\alpha=0.01$ (statistically significant at $\alpha=0.01$ )

$\mathrm{T}_{\text {cal. at } \alpha} \alpha=0.01=2,326\left(T_{\text {cal }}\right.$ at $\left.\alpha=0.01=2.326\right)$

Tabel 2. Uji skala hasil usaha budidaya udang pada musim tanam ke satu dan ke dua di Jawa Timur tahun 1993/1994.

Table 2. Economic scale test of shrimp culture at the first planting season and second planting season in East Java, 1993/1994.

\begin{tabular}{|c|c|c|c|c|}
\hline $\begin{array}{c}\text { Musim tanam } \\
\text { Planting season }\end{array}$ & $\begin{array}{c}\text { Hipotesis } \\
\text { Hypothesis }\end{array}$ & Testing & T.cal. & $\begin{array}{c}\text { Keputusan } \\
\text { Decision }\end{array}$ \\
\hline (1) & $\begin{array}{c}\text { Ho: }: \Sigma \beta_{k}+\Sigma \Sigma \phi_{k j} \leq 1 \\
\text { H1: } \Sigma \beta_{k}+\Sigma \Sigma \phi_{k j}>1\end{array}$ & $\begin{array}{l}\text { CRTS } 2.3285^{* * *} \\
\text { IRTS }\end{array}$ & 0.1272 & Reject Ho \\
\hline (2) & $\begin{array}{l}\text { H1: }: \Sigma \beta_{\mathrm{k}}+\Sigma \Sigma \phi_{\mathrm{kj}}>1 \\
\text { Ho: } \Sigma \beta_{\mathrm{k}}+\Sigma \Sigma \phi_{\mathrm{kj}} \leq 1\end{array}$ & $\begin{array}{l}\text { CRTS } 0.2695 \\
\text { IRTS }\end{array}$ & 0.6037 & Accept $\mathrm{Ho}$ \\
\hline
\end{tabular}

***) signifikan pada $\alpha=0,01$ (statistically significant at $\alpha=0.01$ )

CRTS (constant return to scale)

IRTS (increasing return to scale) 
bandingkan dengan teknologi intensif dan ekstensif. Sedangkan pada musim tanam ke dua, ketiga tingkatan teknologi budidaya udang tidak ada perbedaan efisiensi ekonomi dalam meng. alokasikan masukan produksi (Tabel 1). Hal ini disebabkan oleh kendala teknis atau ekonomi. Poernomo (1988) menyatakan bahwa, lingkungan sangat berpengaruh pada kehidupan udang. Padat penebaran tinggi (intensif) berpengaruh nyata pada kesehatan dan pertumbuhan udang. Makin tinggi padat penebaran makin lambat pertumbuhan udang, sedangkan pada padat penebaran rendah (semiintensif dan ekstensif), kesehatan udang tetap baik.

Secara teknis adalah: (1) pada musim tanam ke dua kualitas air menurun, jika dibandingkan dengan musim tanam ke satu dan (2) padat penebaran teknologi intensif jauh lebih tinggi jika dibandingkan dengan semiintensif dan ekstensif, sehingga masukan produksi yang berubah meningkat, menyebabkan biaya produksi juga meningkat secara proporsional. Dengan pengelolaan secara semiintensif dan ekstensif, lingkungan perairan pantai di sekitar hamparan tambak udang dapat dikatakan tidak banyak berubah mutunya. Lain hal pada pengelolaan teknologi intensif yang tidak hati-hati. Dengan padat penebaran tinggi akan berdampak negatif yang nyata terhadap lingkungan di sekitar hamparan tambak tersebut. Secara ekonomi, biaya investasi teknologi budidaya udang intensif jauh lebih besar terutama dalam masukan tetap berupa konstruksi kolam, bangunan sipil, dan peralatan kincir dibandingkan dengan semiintensif dan ekstensif.

Menurut Malistyani et al. (1993), usaha budidaya udang teknologi intensif tidak efisien jika investasi di bidang konstruksi kolam dan bangunan sipil (mess dan kantor) dibangun secara mewah tanpa memperhatikan bagaimana pengelolaan air dan pakan dilakukan secara benar.

Hasil pengujian menunjukkan bahw:a kondisi skala usaha pertambahan hasil yang naik (increasing return to scale), berarti bahwa setiap penambahan alokasi masukan produksi untuk meningkatkan keluaran (output), yaitu udang akan mengalami kenaikan hasil lebih besar dari pada kenaikan masukan produksi pada musim tanam ke satu (Tabel 2). Selanjutnya, pada musim tanam ke dua, ketiga kategori teknologi budidaya udang tersebut telah berlangsung pada kondisi skala usaha yang tetap (constant return to scale). Hal ini berarti bahwa setiap penambahan alokasi merupakan masukan produksi. selanjut nya keluaran akan mengalami kenaikan yang sama secara proporsional.

\section{KESIMPULAN DAN SARAN}

(1) Pada musim tanam ke satu (musim hujan) teknologi budidaya udang semiintensif lebih efisien dalam mengalokasikan masukan produksi, jika dibandingkan dengan teknologi budidaya udang intensif dan ekstensif. Di pihak lain, pada musim tanam ke dua (musim kemarau) teknologi budidaya udang intensif, semiintensif, dan ekstensif tidak menunjukkan efisiensi ekonomi yang berbeda.

(2) Pada musim tanam ke satu teknologi budidaya udang intensif, semiintensif, dan ekstensif telah berlangsung pada kondisi skala usaha pertambahan hasil yang naik atau increasing return to scale (IRTS).

(3) Mengingat teknologi budidaya udang semiintensif lebih efisien jika dibandingkan dengan teknologi intensif, maka kepada petani atau pengusaha disarankan untuk mengadakan realokasi sumber daya masukan produksi tetap, berupa konstruk si kolam dan bangunan sipil sehingga proyek investasi budidaya udang tidak terlalu besar.

(4) Pengembangan budidaya udang di masa yang akan datang sebaiknya diarahkan kepada teknologi budidaya udang semiintensif, karena teknologi budidaya udang semiintensif lebih efisien dan tangguh bagi kelangsungan usaha dalam jangka panjang.

\section{DAFTAR PUSTAKA}

Anonim. 1992. Lima tahun penelitian dan pe. ngembangan pertanian (1987-1991). Badan Penelitian dan Pengembangan Pertanian Departemen Pertanian RI. Jakarta. hal. 71-80.

Anonim. 1993. Statistik ekspor \& impor hasil perikanan. Direktorat Jendral Perikanan, Departemen Pertanian RI. Jakarta.

Bilas, R.A. 1984. Teori mikro ekonomi. Edisi Kedua. Penerbit Erlangga.Jakarta. 205 hal 
Cholik, F.; A. Poernomo; dan I.P. Kompiang. 1989. Budidaya udang: perlu penanganan yang lebih baik dan efisien. Prosiding Temu Karya Ilmiah Dukungan Penelitian bagi Program Pengembangan Udang. Pusat Penelitian dan Pengembangan Perikanan. Jakarta. hal. 152-155.

Cochran, W.G. 1977. Sampling techniques. Third Edition. John Willey and Sons. New York. p: 89-114

Malistyani,W.; M. Hisyam; M.L. Nurdjana. 1993. Pengaruh budidaya udang terhadap keadaan sosial ekonomi masyarakat. BBAP Jepara. Direktorat Jenderal Perikanan. Departemen Pertanian. 50 hal.

Partagunawan, K. 1990. Analisis usahatani tambak udang windu berdasarkan pola intensifikasi di Kecamatan Indramayu, Kabupaten Indramayu. Tesis Magister. Program Pascasarjana UNPAD. Bandung. 130 hal.
Parrel, C.P.; G.G. Caldito; P.L.Ferrer; G.G. De Guzman; C.S.Sinsioco; and R.H. Tan. 1973. Sampling design and procedures. The Agricultural Development Council (A/D/C). Singapore. p.57-60.

Poernomo, A. 1988. Pembuatan tambak udang di Indonesia. Sumarno, S. dan S.Dahlan (eds.) Seri Pengembangan No.7. Badan Litbang Pertanian, Balai Penelitian Budidaya Pantai, Maros. 30 hal.

Sidhu, S.; and C.A. Baanante. 1981. Estimating farm level input demand and wheat supplay in The Indian Punjab. Using a Translog Profit Function. Amer.J.Agr.Econ. 63 no.2: 237-246.

Simatupang, P. 1988. Penentuan skala usaha dengan fungsi keuntungan: landasan teoritis dengan contoh fungsi Cobb-Douglas dan Translog. Pusat Studi Agroekonomi. Jurnal Agro Ekonomi 1(7): 1-16.

Yusdja,Y., dan B.Saragih, 1983. Skala usaha dan efisiensi ekonomi relative usaha ternak ayam petelur. Jurnal Agro Ekonomi 3(1) : 105 - 127. 